Textures and Microstructures, 1991, Vols 14-18, pp. 493-500 Reprints available from the publisher

Photocopying permitted by license only (c) 1991 Gordon and Breach Science Publishers SA Printed in the United Kingdom

\title{
TEXTURE DEVELOPMENT IN AUSFORMED RIGH STRENGTH STEELS
}

\author{
C.S. DA COSTA VIANA \\ IME - SE/4 - PÇA GENERAL TIBÚRCIO, 80 - URCA \\ RIO DE JANEIRO - RJ - BRAZIL - 22290
}

\section{INTRODUCTION}

Since the original work by Lips and Van Luilen ${ }^{1}$ several authors have shown that great improvements in mechanical properties can be obtained in some steels through the use of ausforming $2,3,4$. The ausforming treatment consists of the strain-hardening of metastable austenite followed by quenching to room temperature. Usually, the deformation takes place in the temperature bay, between the pearlite and the bainite transformation C - branches of the TTT diagram of conveniently alloyed medium carbon steels. High strenght steels can, through ausforming, have both hardness and toughness increased when compared to conventional heat treatment values as shown by Callim et al. 5

During ausforming no recrystallization takes place. The increases in mechanical properties are attributed to a high dislocation density inherited by the martensite and to a fine strain induced carbide precipitation occurring in the austenite. In the case of steel plates, additional strengthening may be developed taking advantage of the transformation texture inheritance of the martensite from the deformed austenite. Zarkades ${ }^{6}$ and $\mathrm{Hu}^{7}$ used this to develop steel armour plates with higher ballistic performance. 
These authors obtained martensitic steel plates with $\{111\}+$ \{112\} textures showing that these components increased with the deformation of the parent austenite matrix. $\mathrm{Hu}$ and Kallend ${ }^{8}$ used crystallite orientation distribution analysis on similar materials and arrived at better descriptions of the textures.

With similar goals, the present work is an extension of that developed by Callim et $a{ }^{5}$ to include higher strains. The deformation was applied by rolling and the transformation textures were quantified by the crystallite orientation distribution function (CODF), using Roe's ${ }^{9}$ method.

\section{MATERIAL AND PROCEDURES}

The steel used was a $0.5 \mathrm{C}-1 \mathrm{Cr}-3 \mathrm{Ni}-0.3 \mathrm{Mo}$ tool steel supplied in the form of annealed $38 \mathrm{~mm}$ diameter bar. From this, $23 \mathrm{~mm}$ hiegh-31mm diameter cylinders were machined and inserted into $50 \mathrm{~mm} \times 80 \mathrm{~mm}$ blocks of AISI 1020 steel. This allowed a perfect handling and control of the thermomechanical treatment.

The specimens were soaked at $1123 \mathrm{~K}\left(830^{\circ} \mathrm{C}\right)$ and quickly transferred to a salt bath at $893 \mathrm{~K}\left(620^{\circ} \mathrm{C}\right)$. There they stayed till temperature homogenization was acheived being then rolled to different reductions and quenched in oil. The rolling procedure was interrupted at about every two passes in order to reheat the specimens in the salt bath. Preliminary tests showed that following this sequence the material would not transform before about 30 minutes. Texture analysis was performed via the crystallite orientation distribution function (CODF) according to the method of Roe ${ }^{9}$. The series 
of spherical harmonics was evaluated up to the 20 th order and no zero-range correction was taken into account. The parent austenite texture was calculated from the CODF of the martensite according to the method described by Davies et a1. ${ }^{10}$ using the Kurdjumov-Sachs orientation relationship without variant selection.

The specimens were coded according to their total deformation using the letter $S$ followed by numbers representing the percent rolling reduction.

\section{RESULTS AND DISCUSSION}

Al1 the ausformed samples showed a plain martensitic microstructure.

Table 1 summarizes the data for the ausformed specimens. It can be seen that the heighest peaks in all textures occur near $\{\overline{3} 32\}\langle 1 \overline{1} 3\rangle$ and $\{\overline{1} 12\}<1 \overline{1} 0\rangle$ and that their height increase with the austenite rolling reduction. A minor component, $\{001\}\langle 1 \overline{1} 0\rangle$, exists in al1 the textures, its heighest value accurring for specimen 588 . The texture severity parameter, TSP, calculated according to Kallend ${ }^{11}$, also increases with the austenite rolling reduction. The TSP measures the general departure of the texture from uniformity in wich condition it is zero.

Callim $^{12}$ studying ausforming textures in a $300-M$ steel found similar results. Figure 1 shows the maximum function height as a function of austenite reduction for both the results of Callim and those of the present work. A steady increase can be observed. 
Figure 2 shows the $\phi=45^{\circ}$ sections of the CODFs for specimens $\mathrm{S} 65$ to $\mathrm{S} 85$. The textures can be described by the two fiber components $\{111\}<u v w>$ and $\{h k l\}<110>$ in a fashion practically identical to that observed in the cold rolling of mild steel. This can be confirmed by comparing the texture of specimen $\mathrm{S} 88$ to that of an $80 \%$ cold rolled A $\ell$ - Killed stee $1^{13}$, in figure 3 . In this figure it can be seen that the texture of the mild steel is slightly more spread along the $\{$ hkl $\}<110\rangle$ fiber and that its $\{001\}<110\rangle$ component is higher. In fact, it is rather interesting to observe the identical sharpnesses of the textures for nearly the same rolling reduction, despite the thouroughly different mechanisms operating in their formation.

During ausforming the dislocation density of the austenite increases, constinuously increasing the number of sites for carbide precipitation. This precipitation occurs during both the deformation and the reheating periods between passes. A strong precipitate-dislocation interaction occurs during each rolling pass. Normally this would lead to randomization of the austenite texture ${ }^{14}$ and, consequently, of the martensite texture. In this work, however, this was not observed. Here, the strong martensite texture implies the preexistance of a sharp austenite texture. The randomizing effect of the carbide particles is thought to have been relaxed by particle coalescence and non - conservative dislocation motion - both enhanced by temperature - which, together with variant selection, lead to the formation of a strong martensite texture.

In figure 3 the austenite texture was predicted from that of the martensite for specimen 588 . The texture can 
undoubtly be recognized as one the copper type. Its lack of high intensities and sharpness stems from the non consideration of variant selection in the transformation program.

Ausforming can, therefore, be a way of developing strong transformation textures in high strength plate steels for special purposes. The anisotropy of elastic properties can be associated with increases in hardness and toughness 5 resulting from a proper combination of percent reduction and deformation temperature to develop a better material.

\section{REFERENCES}

1 - Lips, E.M.H. and Van Zuilen, H, Mt. Prog. 66, (1954), 103.

2 - Zackay, V.F. and Justusson, W.M., Special Report, The Iron and Steel Institute, 1962, p. 14.

3 - Philips, R. and Duckworth, W.E. The effect of alloying additions on the ausforming response of steels. Pronc. 2nd Intern. Symp. on High-Strenght Mat., Berkeley, (1962), p. 307 .

4 - Raymond, L. Gerberich, W.W. and Martin, C.F. The role of carbon in ausforming. Proc. 2nd Intern. Symp. on HighStrenght Mat., Berkeley, (1964), p. 297.

5 - Callim, A.P., Viana, C.S. da S. and Brandão. L. P. M. Thermomechanical treatment of a 300-M steel plate. Proc. 6th Intern. Cong. Heat Treat. of Mat., Chicago, (1988), p. 263.

6 - Zarkades, A. Improved high-strenght armour steel through texturing. (1979). AMMRC TR-79-52.

7 - Hu, H. Effect of controlled rolling on the crystallographic texture and the mechanical and 
ballistic properties of steel armour plates. (1980) AMMRC TR-80-4.

8 - Hu, H. and Kallend, L.S. Transformation textures in thermomechanically processed 5 Ni-steel plates. Proc. 6th ICOTOM, (1981), p. 164.

9 - Roe, R.J. Description of crystallite orientation in polycrystalline materials. J. App. Phys. 36, (1965), 2024.

10- Davies, G.J., Kallend, J.S. and Morris, P.P., Acta Met., 24, (1976), 159 .

11- Kallend, J.S., PhD thesis, Cambridge, England (1970).

12- Callim, A.P., MSc thesis, IME, Brazil, (198).

13- Goodwill, D.J. PhD Thesis, Cambridge, England (1972).

14- See "The Influence of Carbide Distribution on Texture Formation in a fast Annealed Al-Killed Steel" in these proceedings.

TABLE 1. Main components of the ausforming textures.

\begin{tabular}{|c|c|c|c|}
\hline Specimen & component & CODF height & TSP \\
\hline \multirow{2}{*}{ S68 } & $\{\overline{3} 32\}<1 \overline{1} 3>$ & 2,5 & 0,8 \\
& $\{\overline{2} 23\}<1 \overline{1} 0>$ & 3,5 & \\
S70 & $\{332\}<113>$ & 4,0 & 1,0 \\
& $\{112\}<110>$ & 4,0 & \\
S81 & $\{\overline{3} 32\}<1 \overline{1} 3>$ & 6,0 & 1,5 \\
& $\{\overline{1} 12\}<1 \overline{1} 0>$ & 6,0 & \\
S85 & $\{\overline{3} 32\}<1 \overline{1} 3>$ & 6,0 & 1,6 \\
& $\{\overline{1} 12\}<1 \overline{1} 0>$ & 7,0 & \\
S88 & $\{\overline{3} 32\}<1 \overline{1} 3>$ & 6,0 & 1,6 \\
& $\{\overline{1} 12\}<1 \overline{1} 0>$ & 8,0 & \\
\hline
\end{tabular}




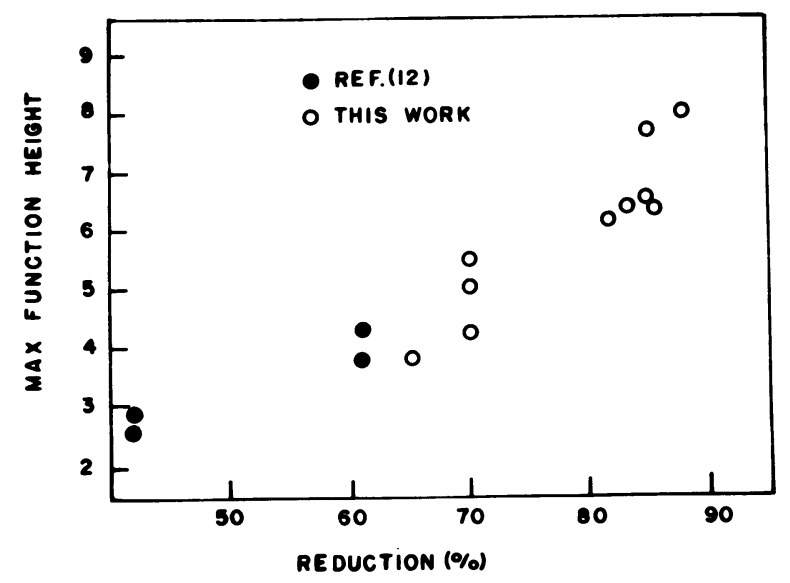

FIGURE 1 Function height versus ausforming reduction
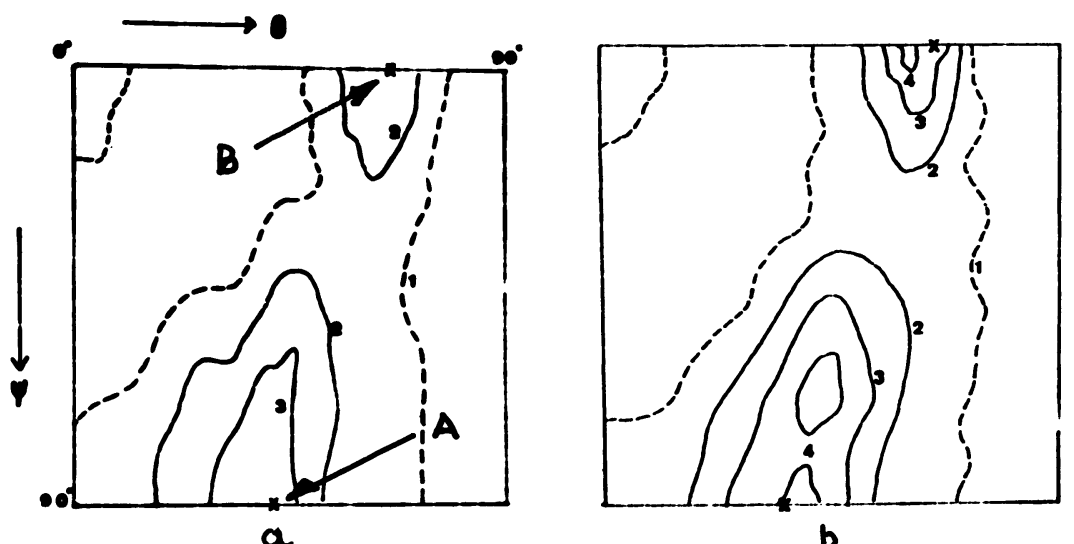

b
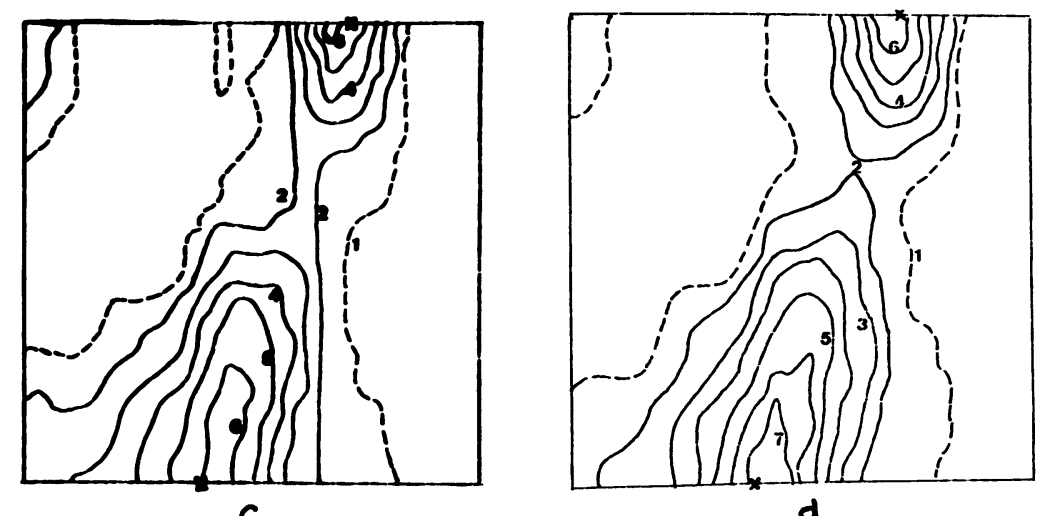

d

Fiqure 2 Texture of specimens (a) $565:$ (b) 570 (c) $581:$ (d) $585 ; \varnothing=45^{\circ}$ 

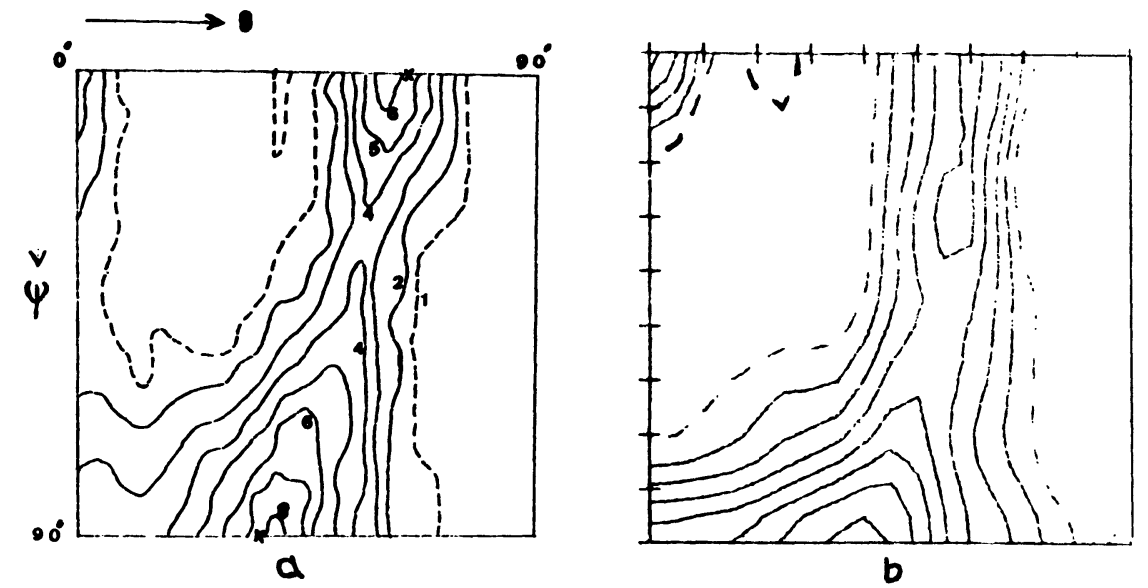

Figure $3 \phi=45$ ? sections for (a) 588 and (b) $80 \%$ cold rolled killed steel
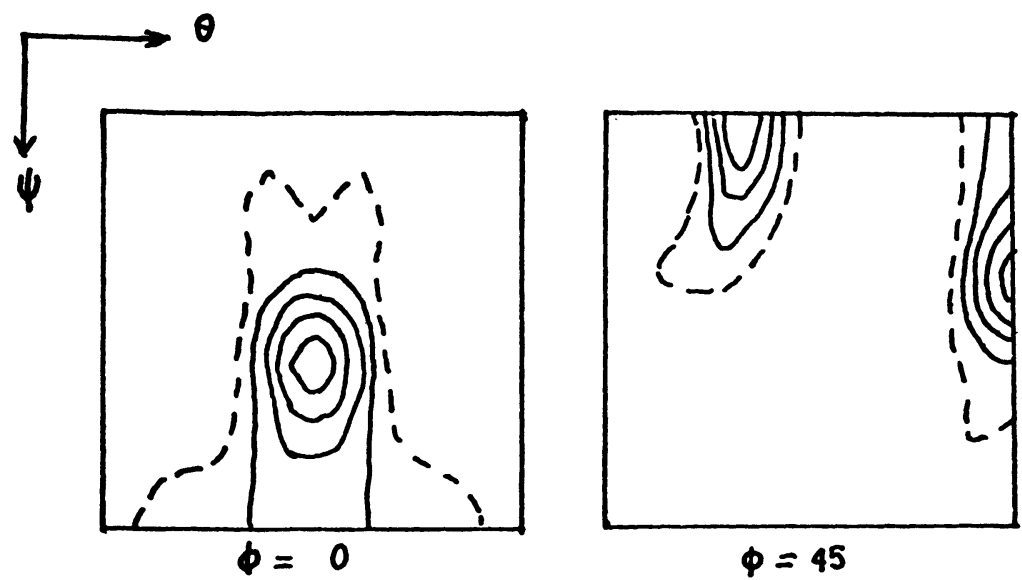

Figure 4 K-S transformation texture predicted from texture of specimen $\$ 88$ 